\title{
El plancton de las lagunas de gravera y el fósforo: el enriquecimiento de las paradojas
}

\author{
M. Alvarez Cobelas ${ }^{1}$, J. García-Avilés ${ }^{2}$ y E. Ortega Mayagoitia ${ }^{3}$ \\ ${ }^{1}$ Centro de Ciencias Medioambientales, CSIC, Serrano 115 dpdo., 28006 Madrid, Spain, malvarez@ccma.csic.es \\ ${ }^{2}$ Centro de Investigaciones Ambientales de la Comunidad de Madrid, San Sebastián 71, Soto del Real, \\ 28791 Madrid, Spain, ciam03@bio.ucm.es \\ ${ }^{3}$ Fac. Estudios Superiores de Iztacala, UNAM, Avda. Los Barrios s/n., Los Reyes Iztacala, 54090 \\ Tlalnepantla, México, eortega@correo.unam.mx
}

\section{RESUMEN}

Durante las últimas décadas se han formulado explícitamente varias hipótesis sobre el funcionamiento de las comunidades pelágicas lacustres en relación con el enriquecimiento en fósforo. Entre ellas, se cuentan: $1^{\mathrm{a}}$ ) la relación directa entre fósforo y biomasa planctónica, $2^{\mathrm{a}}$ ) los máximos de la riqueza específica planctónica a niveles intermedios de fósforo, $3^{\mathrm{a}}$ ) la desestabilización de los grupos funcionales de la red trófica debida al enriquecimiento en fósforo (ó "paradoja del enriquecimiento"), $4^{\mathrm{a}}$ ) el hecho de que la biomasa planctónica en todos los niveles sea el resultado de la interacción entre el recurso limitante (el fósforo, en este caso) y la red trófica encabezada por los peces ictiófagos, y $5^{\text {a }}$ ) la marcada influencia del enriquecimiento y de los peces ictiófagos sobre el espectro de tamaños planctónicos. Con objeto de comprobar estas hipótesis, realizamos un estudio estacional durante año y medio sobre el plancton de 16 lagunas de gravera situadas en el valle del río Jarama (Madrid), las cuales presentan un gradiente claro de fósforo total promedio (36-2500 $\mu \mathrm{g} \mathrm{P} / \mathrm{L})$ y pueden o no albergar peces ictiófagos, aunque casi todas tengan ciprínidos. La $1^{a}$ hipótesis sólo se cumplió para bacterias, fitoplancton y rotíferos, pero no para las restantes comunidades planctónicas. La $2^{\mathrm{a}}$ hipótesis se refutó, pues los máximos de riqueza específica se presentaron en las lagunas hipertróficas. La $3^{\mathrm{a}}$ hipótesis no se comprobó y, en el caso de bacterias y fitoplancton consumible por herbívoros, tuvo lugar una estabilización de los mismos con el aumento de fósforo; probablemente, el efecto estabilizador de la omnivoría debida a copépodos y a ciprínidos fuera el responsable de este resultado. Los peces ictiófagos afectaron favorablemente a la biomasa de cladóceros, no alcanzando su efecto a los niveles inferiores de la red, controlados claramente por el fósforo, lo cual prestó apoyo a la idea de la interacción entre fuerzas ascendentes y descendentes de la red trófica, pero refutó la idea de la cascada trófica. Tanto el fósforo como los peces ictiófagos influyeron sobre el espectro de tamaños de modo antagónico, lo cual complicó la $5^{\mathrm{a}}$ hipótesis. La conclusión general de este ejercicio de contraste de hipótesis es -además de la obvia de continuar investigando las redes tróficas planctónicas- que necesitamos hipótesis más globales en apoyo epistemológico de este enriquecimiento de las paradojas que hemos observado.

Palabras clave: Fósforo total, redes tróficas, riqueza específica, biomasa, peces ictiófagos

\begin{abstract}
Several hypotheses have been outlined on the relationship of lake communities and phosphorus enrichment in recent years. Some of them are the following: i) a positive relationship between phosphorus and planktonic biomass, ii) species richness peaks at intermediate phosphorus concentrations, iii) the destabilisation of food web functional groups arising from phosphorus enrichment (called the paradox of enrichment), iv) the plankton biomass as the outcome of interactions between the limiting resource (phosphorus in most lakes) and the food web, and v) the remarkable influence of phosphorus enrichment and piscivorous fish on planktonic size spectra. To test these hypotheses, we carried out a seasonal study on plankton communities of sixteen gravel-pit lakes for fifteen months in the river Jarama plain (Madrid, Central Spain). These lakes showed a wide range of average phosphorus contents (36-2500 $\mu \mathrm{g} P / L)$, piscivorous fish lived in some of them and most harbour benthic, omnivorous ciprinids. Hypothesis $i$ was only demonstrated for bacteria, phytoplankton and rotifers. Hypothesis ii was refuted since species richness peaks occurred in hypertrophic lakes. Hypothesis iii was not supported by our data, and we even found a stabilisation of bacterial and edible phytoplankton populations along with phosphorus enrichment, such a stabilisation being a likely result of omnivory by copepods and ciprinids. As expected, piscivorous fish influenced cladoceran and bacterial density whereas phosphorus enrichment increased phytoplankton biomass, but the top-down effect did not affect phytoplankton, rotifers and copepods, thus supporting the bottom-up:top-down model against the trophic cascade model. Both phosphorus and piscivorous fish
\end{abstract}


impinged on planktonic size spectra, albeit in an antagonistic way, and hence hypothesis $v$ must be made more comprehensive. In addition to the obvious necessity of further studies on planktonic food webs, this exercise of hypothesis testing suggests that more comprehensive hypotheses should be built to support epistemologically the enrichment of paradox observed.

Keywords: Total phosphorus, food web, species richness, biomass, piscivorous fish, Spain

La pulce d'acqua'
che lo sa
l'ombra ti renderà
Angelo Branduarti

\section{INTRODUCCIÓN}

El renovado interés que han suscitado las redes tróficas durante las últimas dos décadas ha generado una serie de estudios y de hipótesis interesantes (Oksanen et al., 1981; Cohen et al., 1990; Fretwell, 1987; De Angelis, 1992; Andersen, 1997), ha vuelto a poner de actualidad a Lindeman y sus enfoques (Lindeman, 1942) y ha hecho avanzar el conocimiento de las respuestas del ecosistema lacustre a los nutrientes y su interacción con los peces (Carpenter \& Kitchell, 1993a), tras el impulso inicial de los estudios de eutrofización de hace cuatro décadas (Vollenweider, 1968).

En particular, el enriquecimiento de los lagos en el nutriente limitante -que suele ser el fósforo en el medio acuático continental (Hecky \& Kilham, 1988)- y la respuesta de las redes tróficas pelágicas a dicho enriquecimiento han producido varias hipótesis relacionadas con distintos aspectos de la estructura de la comunidad pelágica (riqueza específica, biomasa, tamaños, etc.). Algunas de ellas son las siguientes:

$\left.1^{a}\right)$ Relación directa entre el enriquecimiento y la biomasa promedio de todos los componentes de la comunidad planctónica (Hanson \& Peters, 1984; Smith, 1991).

$2^{a}$ ) Los máximos de la riqueza específica de las comunidades tienen lugar a niveles intermedios del nutriente limitante (Dodson et al., 2000).

$3^{\mathrm{a}}$ ) El aumento del nutriente limitante produce una desestabilización de los grupos funciona- les de la red trófica (Persson et al., 2001). Este es un aspecto de la denominada "paradoja del enriquecimiento" (Rosenzweig, 1971), el cual carece de valor denotativo en su primer término al no indicar en dónde reside el carácter paradójico apuntado. Lo que se deduce de la propuesta de Rosenzweig es que con el aumento del nutriente limitante no habría motivos para la existencia de efectos desestabilizadores en la red trófica, pero esa manera de pensar tiene un componente desiderativo implícito: si hay más recurso, debería haber para todos los elementos, cosa que no es así ni en la naturaleza ni en la sociedad. Cuando enunció su paradoja, Rosenzweig estaba claramente influido por las ideas prevalecientes entonces sobre el "balance de la naturaleza" (Williams, 1964), las cuales implicaban nociones de equilibrio ecológico que no han resistido el paso del tiempo (De Angelis \& Waterhouse, 1987).

$4^{a}$ ) La biomasa planctónica en todos los niveles de la red pelágica es el resultado de la interacción entre el enriquecimiento nutritivo y el efecto de los peces. Esta hipótesis se ha formulado de dos maneras: la "cascada trófica", que actúa mediante la depredación por selección del tamaño en los distintos niveles trófi$\cos$ y que influye sobre la competencia por los nutrientes entre las especies de fitoplancton (Carpenter et al., 1985), y la interacción entre fuerzas ascendentes ("bottom-up") y descendentes ("top-down"), debida a los efectos de la disponibilidad de nutrientes en la base y de la depredación en la cúspide de la cadena trófica (McQueen et al., 1986).

$\left.5^{a}\right)$ Tanto el enriquecimiento en el nutriente limitante como la cascada trófica afectan al espectro de tamaños planctónicos (Mazumder et al., 1988). 
Nosotros nos propusimos comprobar estas hipótesis en un conjunto de lagunas de gravera próximas a Madrid, muy variables en cuanto a su concentración de fósforo total, parte de las cuales albergaban peces ictiófagos y todas ellas con comunidades planctónicas bien desarrolladas.

\section{LUGAR DE ESTUDIO}

El Parque Regional del Sureste de Madrid es un conjunto de ríos, lagos y embalses enclavado en el tramo bajo del río Jarama, unos $20 \mathrm{~km}$ al sureste de la ciudad. Uno de los aspectos más característicos del paisaje es la extracción de áridos, que ha dado lugar a la formación de un número de lagos superior a 200 en los últimos 45 años, aunque también haya meandros abandonados. Su extensión se halla entre 0.1 y más de $100 \mathrm{Ha}$, alcanzando profundidades de hasta 20 metros. Pueden estratificarse térmicamente o ser polimícticos. Su salinidad oscila entre 1.5 y $16 \mathrm{~g} / \mathrm{L}$ y su condición trófica, desde la oligo-mesotrofia hasta la hipertrofia (rango de fósforo total promedio: 36-2500 $\mu \mathrm{g}$ P/L). Carecen de alimentación superficial, de modo que el agua procede del acuífero y de los ríos próximos, ambos ricos en nutrientes. Tienen unas comunidades vegetales y animales bien desarrolladas y en algunos de ellos hay peces ictiófagos (Esox lucius L. y Micropterus salmoides Lacèpéde), estando desprovistos de peces planctófagos en el medio pelágico y poseyendo varias especies de ciprínidos.

Los 16 lagos elegidos para este estudio (Fig. 1), ya abandonados por la actividad minera, presentaban comunidades pelágicas complejas,

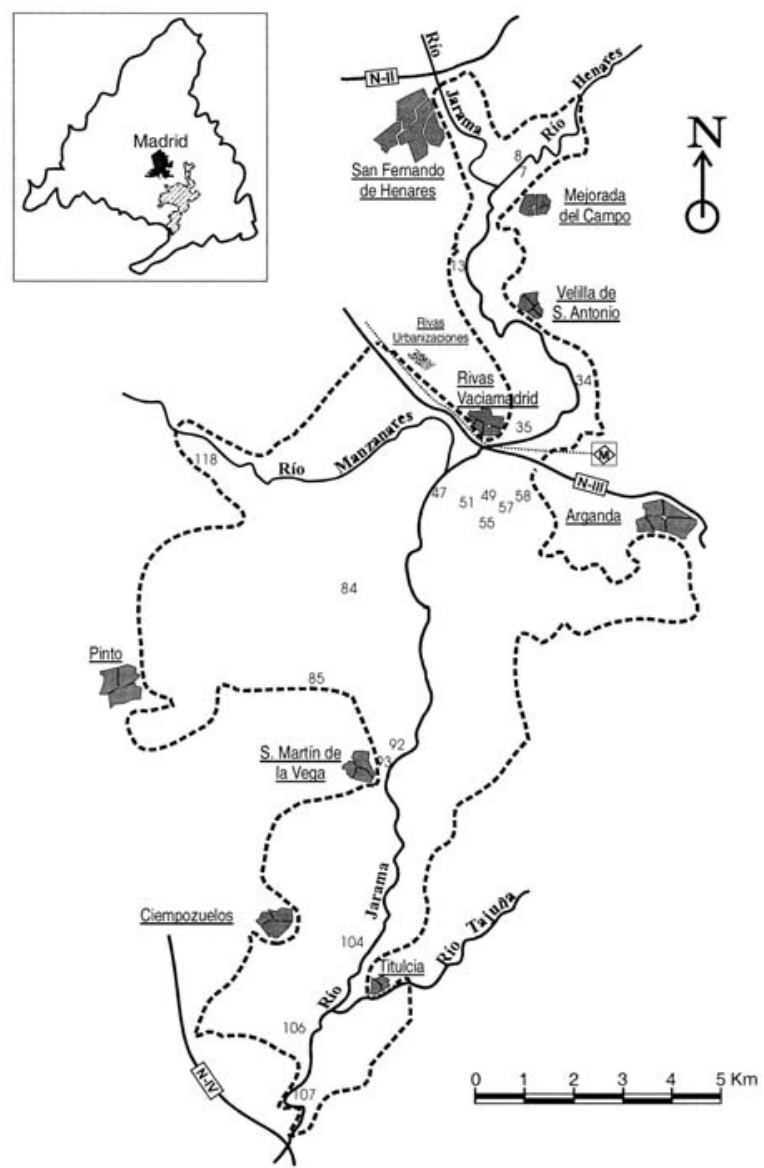

Figura 1. Lugar de estudio; los números son los mismos de la Tabla 1. Study site. Lake numbers are those of Table 1. 
constituidas por bacterias, fitoplancton, zooplancton y peces. Para más información sobre los lagos, véanse las Tablas 1-2 y los trabajos de Roblas \& García-Avilés (1997), García-Avilés et al. (1999) y Alvarez Cobelas et al. (2000).

\section{MATERIAL Y MÉTODOS}

\section{Trabajo de campo y análisis de laboratorio}

Los muestreos se realizaron con periodicidad aproximadamente trimestral durante año y medio en 16 lagos del Parque Regional del Sureste (Tablas 1-2). Cada campaña se realizó durante 35 días. Tras estimar la transparencia del agua con un disco de Secchi y elaborar perfiles de temperatura y oxígeno disuelto con un equipo YSI-59, las muestras de agua y plancton se tomaron de metro en metro en la columna de agua con una botella oceanográfica Niskin de 5 litros de capacidad. Usando los perfiles de temperatura, se definieron las capas térmicas y se integraron alícuotas de cada profundidad con objeto de formar muestras homogéneas para el análisis de las variables químicas correspondientes al epilim- nion, la termoclina y el hipolimnion. Para el estudio del plancton, las alícuotas, tomadas de metro en metro, se ensamblaron en muestras integradas a toda la columna de agua. En el caso del zooplancton se filtraron al menos 30 litros por lago y fecha de muestreo a través de filtros de Nytal de 50 micras de poro. El fitoplancton fue fijado con lugol sin ácido acético; las bacterias y el zooplancton, con formol al $4 \%$.

Para los análisis químicos, que fueron realizados inmediatamente, seguimos los protocolos de APHA (1989: 2230.B, 4500-P.E, 3500Na.D，3500-Ca.D，3500-Mg.C，3500-Na.D, 4500-SO4.E, 4500-Cl.B), Bachmann \& Canfield (1992, nitrógeno total) y Marker et al. (1980, clorofila $a$ ). Los análisis de aniones y cationes se llevaron a cabo tras filtrar las muestras por filtros de fibra de vidrio de 0.45 micras de poro. La determinación de la clorofila se efectuó mediante espectrofotometría tras la filtración de hasta 2 litros de agua, en el caso de los ambientes más oligotróficos, a través de filtros de fibra de vidrio de 0.45 micras de poro, y la subsiguiente extracción del pigmento con metanol al $90 \%$ en caliente; no hubo corrección feopigmentaria.

Tabla 1. Lagos estudiados. La profundidad referida es la del punto de muestreo; en las graveras es muy difícil determinar la profundidad máxima sin realizar ecosondeos detallados. Study sites in the Southeastern Regional Park of Madrid (Central Spain). Reported depth is at the sampling site because it is very hard to find the maximal depth in gravel-pits without detailed echosounding.

\begin{tabular}{|c|c|c|c|c|c|}
\hline $\begin{array}{l}\text { NOMBRE DEL LAGO/ } \\
\text { Name }\end{array}$ & $\begin{array}{l}\text { NÚMERO/ } \\
\text { Lake number }\end{array}$ & $\begin{array}{l}\text { CUENCA/ } \\
\text { Watershed }\end{array}$ & $\begin{array}{l}\text { COORDENADAS UTM/ } \\
\text { UTM Coordinates }\end{array}$ & $\begin{array}{l}\text { SUPERFICIE (Ha)/ } \\
\text { Lake size }(\mathrm{Ha})\end{array}$ & $\begin{array}{l}\text { PROFUNDIDAD }(\mathrm{m}) / \\
\text { Depth }(m)\end{array}$ \\
\hline Presa del río Henares-1 & 7 & Henares & 30TVK583735 & 4.00 & 0.75 \\
\hline Presa del río Henares-2 & 8 & Henares & 30TVK582737 & 0.26 & 1.5 \\
\hline Rivas-1 (Las Yeseras) & 13 & Jarama & 30TVK560712 & 1.00 & 1 \\
\hline El Campillo-1 & 35 & Jarama & 30TVK574636 & 32.00 & 16 \\
\hline El Porcal-9 & 47 & Jarama & 30TVK546610 & 120.00 & 10 \\
\hline Las Madres-1 & 49 & Jarama & 30TVK566613 & 3.00 & 12 \\
\hline Las Madres-3 & 51 & Jarama & 30TVK562610 & 1.50 & 8 \\
\hline Camping Lagos-1 & 55 & Jarama & 30TVK564607 & 8.00 & 12 \\
\hline Muñoz & 57 & Jarama & 30TVK570617 & 5.00 & 12 \\
\hline Villafranca & 58 & Jarama & 30TVK573618 & 3.00 & 5 \\
\hline Embalse de Gózquez & 85 & Jarama & 30TVK494546 & 2.50 & 1.5 \\
\hline San Martín de la Vega-7 & 92 & Jarama & 30TVK528521 & 0.67 & 1.25 \\
\hline Parque Tierno Galván & 93 & Jarama & 30 TVK522520 & 2.00 & 10 \\
\hline Las Arriadas (Ciempozuelos-1) & 104 & Jarama & 30TVK510442 & 9.00 & 12 \\
\hline Soto de las Cuevas & 107 & Jarama & 30TVK479385 & 12.00 & 4 \\
\hline Los Frailes & 118 & Manzanares & 30TVK475618 & 0.02 & 1 \\
\hline
\end{tabular}




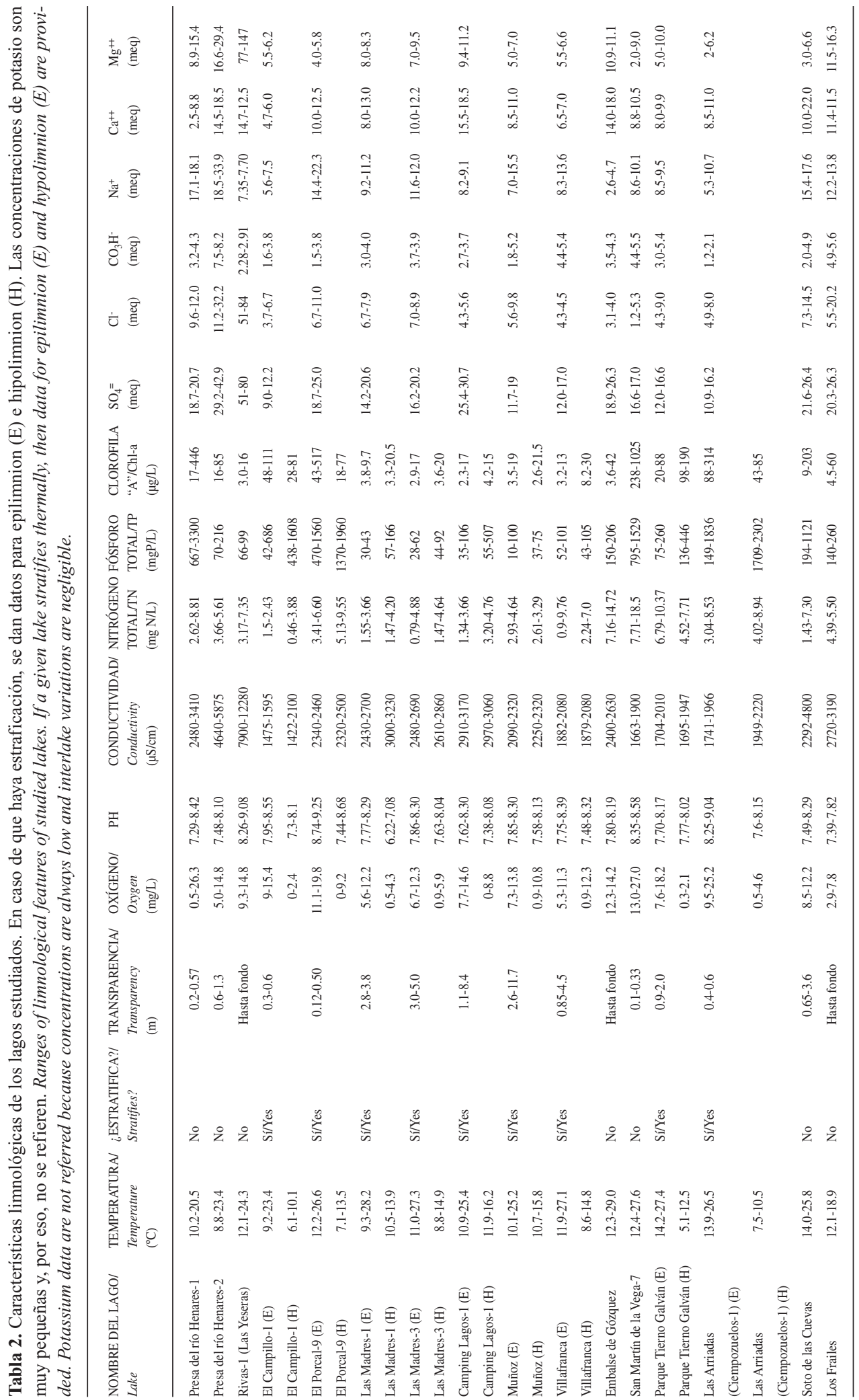


Las bacterias se contaron mediante microscopía de fluorescencia tras tinción con acridina (Hobbie et al., 1977). El resto de las fracciones planctónicas se identificó (sólo en el caso de fitoplancton y rotíferos) y contó en cámaras Utermöhl de capacidad variable (15-100 mL) mediante microscopía invertida (Rott, 1981). Para bacterias, pico y fitoplancton se contaron 400 individuos por cada especie principal, lo cual genera un error aproximado del 10\% siguiendo una distribución teórica de Poisson (Lund et al., 1957); todos los individuos de rotíferos y crustáceos presentes en cada muestra se contaron. Las biomasas de todas las fracciones se evaluaron siguiendo los métodos de Bratbak (1985), Hillebrand et al. (1999) y McCauley (1984), midiendo previamente las dimensiones de 30 ejemplares de cada especie.

\section{Comprobación de hipótesis}

\section{$1^{a}$ Hipótesis: Relación entre fósforo y biomasa planctónica}

El gradiente de fósforo se estimó a partir del promedio de fósforo total del epilimnion para un ciclo anual de cada lago, o de la capa mezclada si aquél no estaba estratificado. Los lagos se ordenaron de modo creciente según su concentración promedio de fósforo total y las biomasas promedio de cada fracción planctónica estudiada se proyectaron sobre ese eje, estimando un coeficiente de determinación -tras una transformación bilogarítmica de los datos- para cada una de las comunidades y en relación con el gradiente de fósforo. A fin de sortear el problema de la posible correlación espúrea entre fósforo total y biomasa planctónica (Prairie \& Bird, 1989), realizamos un simple análisis de correlación con los datos de fósforo reactivo soluble, medido a partir de las mismas muestras de agua utilizadas para el análisis del fósforo total, y los datos de éste, dándonos como resultado un coeficiente de determinación de 0.92 $(\mathrm{p}<0.05)$. Debido a este resultado, por ser el fósforo total el indicador clásico de la eutrofia en los lagos y porque nos interesaba más el gradiente relativo y no los datos cuantitativos, decidimos usarlo como índice del enriquecimiento en fósforo de los lagos estudiados.

\section{$2^{a}$ Hipótesis: La máxima riqueza específica se presenta a niveles intermedios de fósforo}

Usando el fitoplancton y los rotíferos, que fueron las únicas comunidades determinadas a nivel de especie, representamos la riqueza total de cada grupo (resultado de reunir los datos de presenciaausencia de todos los muestreos) frente al promedio de fósforo total epilimnético. Si se cumpliera la hipótesis propuesta, debería observarse una distribución unimodal de los datos (véase el tipo de análisis estadístico en la Tabla 3). Dado que algunos autores han sugerido que el tamaño del lago y/o su profundidad podrían estar relacionados con la riqueza en especies (Browne, 1981), también comprobamos este extremo, con objeto de saber si -además del grado trófico- las caracte-

Tabla 3. Análisis estadísticos usados en este estudio. Todos los datos se han transformado logarítmicamente, excepto para la riqueza específica. CV: coeficiente de variación. Statistical tests; all data have been log-transformed, except for species richness. CV: coefficient of variation.

\begin{tabular}{cl} 
Hipótesis/Hypothesis & Procedimiento/Procedure \\
\hline $1^{\mathrm{a}}$ & Correlación de Pearson/Pearson correlation \\
$2^{\mathrm{a}}$ & Correlación de Pearson/Pearson correlation \\
$3^{\mathrm{a}}$ & ANOVA de un factor sobre el CV de la biomasa de los grupos funcionales/One-way ANOVA \\
& on biomass CV of functional groups \\
$4^{\mathrm{a}}$ & ANOVA de dos factores sobre la biomasa/Two-way ANOVA on biomass data \\
$5^{\mathrm{a}}$ & ANOVA de dos factores sobre las pendientes de Pareto de las distribuciones de tamaño \\
& del plancton/Two-way ANOVA on Pareto slopes of plankton size spectra
\end{tabular}


rísticas morfométricas y la supuesta mayor complejidad de nichos asociada a un mayor tamaño del ecosistema afectan a la riqueza específica de las comunidades planctónicas.

\section{$3^{a}$ Hipótesis: El enriquecimiento en fósforo} desestabiliza los grupos funcionales de las redes tróficas planctónicas

Definimos inicialmente una serie de grupos funcionales: bacterias y picoplancton (tamaño del eje mayor, inferior a 2 micras), fitoplancton consumible por herbívoros (tamaño del eje mayor, inferior a 20 micras) excluyendo el picoplancton, fitoplancton no consumible (tamaño del eje mayor, superior a 20 micras), fitoplancton total, rotíferos herbívoros, rotíferos carnívoros (siguiendo a Pourriot, 1977), rotíferos totales (la suma de ambos), copépodos, cladóceros grandes (tamaño superior a 1000 micras, Daphnia spp. fundamentalmente), cladóceros pequeños (los demás), cladóceros totales (la suma de ambos), heterótrofos totales (la suma de zooplancton y bacterias). Luego, calculamos la media y la desviación típica de las biomasas de cada uno de estos grupos para todas las fechas de recogida de muestras. La des- estabilización se cuantificó usando el coeficiente de variación $(\mathrm{CV})$ de la densidad de cada grupo funcional como indicador para todo el periodo de estudio. Así, un grupo se consideraría más desestabilizado que otro si su CV fuera superior al del otro. Hemos definido dos niveles de fósforo para los lagos (lagos meso-eutróficos $=$ fósforo total promedio $<100 \mu \mathrm{g} \mathrm{P} / \mathrm{L}$; lagos hipertróficos = fósforo total promedio $>100 \mu \mathrm{g} \mathrm{P} / \mathrm{L}$ ) y el análisis estadístico realizado figura en la Tabla 3.

\section{$4^{a}$ Hipótesis: La biomasa planctónica es el resultado de la respuesta al nutriente limitante y a la red trófica}

Se procedió usando las biomasas de los grupos principales (bacterias, fitoplancton, rotíferos, copépodos, cladóceros y heterótrofos totales) estimadas en cada muestreo. Para comprobar la hipótesis se usaron como factores el nivel de fósforo ya citado y la presencia o ausencia de peces ictiófagos (Tabla 3). Esta información se obtuvo a partir de los datos de presencia-ausencia de peces ictiófagos referidos en el trabajo de García-Avilés et al. (1999), además de otras observaciones personales.

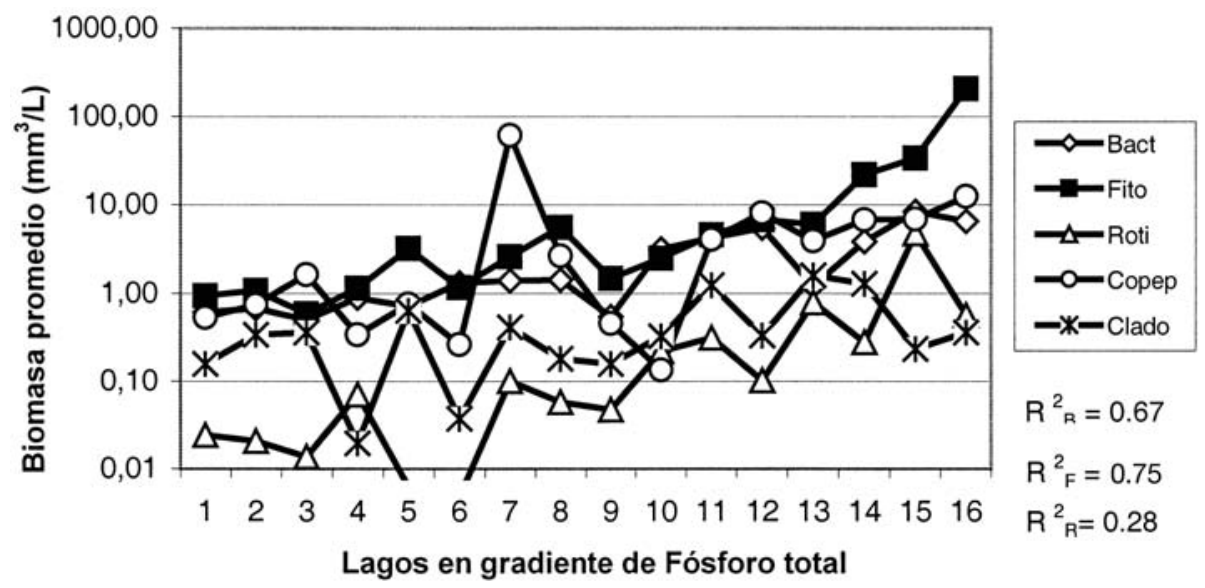

Figura 2. Biomasa promedio de los distintos grupos del plancton a lo largo del gradiente promedio de fósforo total en el Parque Regional del Sureste de Madrid. Hemos calculado usando una transformación log-log el coeficiente de determinación entre fósforo y la biomasa de cada grupo, pero sólo se han representado los resultados estadísticamente significativos (B: bacterias; F: fitoplancton; R: rotíferos). Average biomass of plankton groups as related with total phosphorus gradient of Southeastern Madrid lakes. Statistically significant coefficients of determination (bacteria-B, phytoplankton-F, and rotifers-R), calculated after log-log transformation, are shown. 
Tabla 4. Análisis de la varianza para comprobar la posible desestabilización de las redes tróficas debido al enriquecimiento en fósforo. Se han usado dos niveles para este elemento (lagos con promedio de fósforo total $<100 \mu \mathrm{g} \mathrm{P} / \mathrm{L}$ y lagos por encima de esa cifra). Aunque se han hecho los análisis con todos los grupos funcionales del plancton, sólo se representan aquí los resultados estadísticamente significativos. One-way ANOVA to test the paradox of P-enrichment on the food web. Two levels of phosphorus have been chosen, namely, lakes with less than $100 \mu \mathrm{g}$ $P / L$ and lakes with TP higher than such a figure. Only statistically significant results are shown.

\begin{tabular}{cccccc}
\hline \multicolumn{5}{c}{ BACTERIAS/BACTERIA } \\
MSS & $\mathrm{F}$ & $\mathrm{p}$ & \multicolumn{3}{c}{ Signo/Sign } \\
Fósforo total/TP & 0.10 & 5.12 & 0.043 & - \\
\hline \multirow{3}{*}{ FITOPLANCTON CONSUMIBLE/EDIBLE PHYTOPLANKTON } \\
Fósforo total/TP & 0.15 & 8.01 & 0.015 & - \\
\hline
\end{tabular}

$5^{a}$ Hipótesis: El recurso limitante y los peces ictiófagos influyen sobre la distribución de tamaños planctónicos

Comenzamos calculando las distribuciones de tamaño para cada lago y fecha de muestreo, usando la técnica de Pareto (Vidondo et al., 1997). Los coeficientes de determinación de todas las distribuciones variaron entre 0.78 y 0.99 . El tipo de análisis estadístico realizado figura en la Tabla 3.

\section{RESULTADOS}

La $1^{\text {a }}$ hipótesis no fue confirmada totalmente. Sólo la biomasa promedio de bacterias, fito- plancton y rotíferos aumenta con el enriquecimiento en fósforo y, para la última comunidad, la varianza explicada es pequeña, aunque significativa (Fig. 2; p < 0.05).

No hemos apreciado una distribución unimodal de la riqueza específica de rotíferos y fitoplancton respecto al enriquecimiento en fósforo de los lagos (Fig. 3), que tampoco aparece aunque realicemos una transformación bilogarítmica. Más bien, parece haber una relación directa entre fósforo y riqueza, incluso en ambientes muy hipertróficos, como se aprecia en las gráficas de la Figura 3. Así que este conjunto de datos refutaría la $2^{\mathrm{a}}$ hipótesis. Tampoco hemos encontrado relación estadísticamente significativa entre riqueza específica y tamaño o profundidad de los lagos $\left(\mathrm{r}^{2}=0.04-0.006, \mathrm{p}>0.05\right)$.
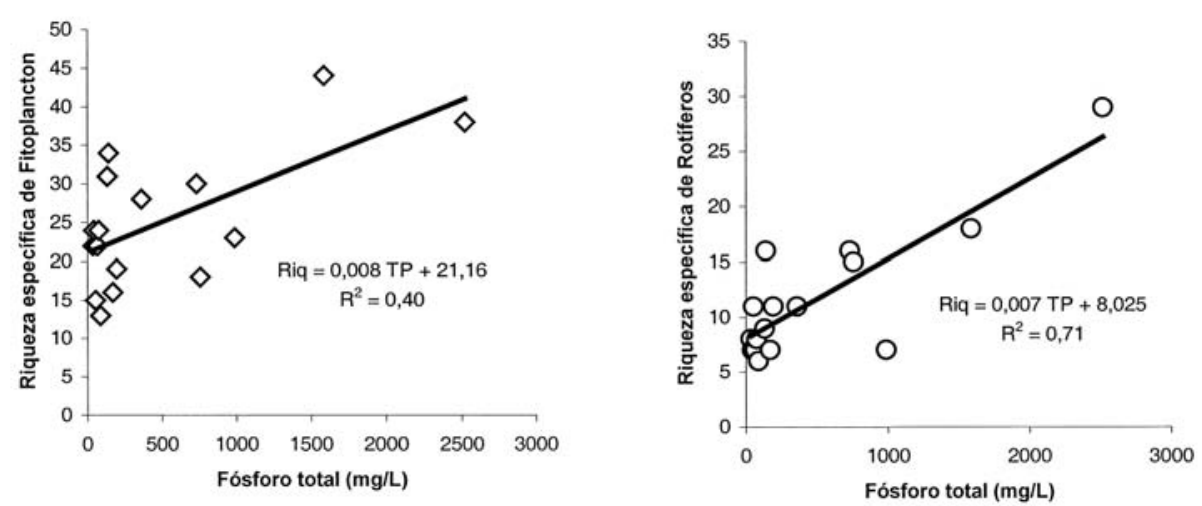

Figura 3. Riqueza específica de fitoplancton y rotíferos en los lagos del Sureste de Madrid en relación con el fósforo total promedio de los mismos. Se han estimado la regresión de Bartlett y su coeficiente de determinación para ambos grupos. La transformación logarítmica no varía sustancialmente este resultado y por eso no se muestra. Plot of species richness of phytoplankton and rotifers vs average total phosphorus in Southeastern Madrid lakes. Bartlett regression and the determination coefficient have been estimated for both species groups. Log-log plots do not change the picture and hence they are not shown. 
Tabla 5. ANOVA de dos factores para comprobar los efectos del enriquecimiento en fósforo y la presencia de peces ictiófagos sobre la biomasa de los principales grupos taxonómicos planctónicos. Datos transformados logarítmicamente. Puede haber dos tipos de interacción factorial y, de ahí, los dos signos en el apartado Fósforo * Peces. Twoway ANOVA on log-transformed data to test the effects of phosphorus enrichment and the occurrence of piscivorous fish on plankton biomass. Two different outcomes may occur in factor interaction and thus two signs are given.

\begin{tabular}{|c|c|c|c|c|}
\hline BACTERIAS/Bacteria & MSS & $\mathrm{F}$ & $\mathrm{p}$ & Signo/Sign \\
\hline $\begin{array}{l}\text { Fósforo total/TP } \\
\text { Peces/Fish } \\
\text { TP * Fish }\end{array}$ & $\begin{array}{l}0.32 \\
1.63 \\
0.14\end{array}$ & $\begin{array}{l}1.10 \\
5.63 \\
0.49\end{array}$ & $\begin{array}{l}0.30 \\
0.02 \\
0.49\end{array}$ & - \\
\hline $\begin{array}{l}\text { FITOPLANCTON/Phytoplankton } \\
\text { Fósforo total/TP } \\
\text { Peces/Fish } \\
\text { TP * Fish }\end{array}$ & $\begin{array}{l}4.36 \\
0.95 \\
1.02\end{array}$ & $\begin{array}{l}9.58 \\
2.08 \\
2.23\end{array}$ & $\begin{array}{l}0.003 \\
0.15 \\
0.14\end{array}$ & + \\
\hline $\begin{array}{l}\text { ROTIFEROS/Rotifers } \\
\text { Fósforo total/TP } \\
\text { Peces/Fish } \\
\text { TP * Fish }\end{array}$ & $\begin{array}{r}13.36 \\
0.06 \\
0.52\end{array}$ & $\begin{array}{r}20.74 \\
0.10 \\
0.81\end{array}$ & $\begin{array}{l}0.00003 \\
0.75 \\
0.37\end{array}$ & + \\
\hline $\begin{array}{l}\text { CLADÓCEROS/Cladocerans } \\
\text { Fósforo total/TP } \\
\text { Peces/Fish } \\
\text { TP * Fish }\end{array}$ & $\begin{array}{l}4.01 \\
5.85 \\
0.85\end{array}$ & $\begin{array}{l}3.44 \\
5.01 \\
0.73\end{array}$ & $\begin{array}{l}0.07 \\
0.03 \\
0.40\end{array}$ & + \\
\hline $\begin{array}{l}\text { COPÉPODOS/Copepods } \\
\text { Fósforo total/TP } \\
\text { Peces/Fish } \\
T P * \text { Fish }\end{array}$ & $\begin{array}{l}5.63 \\
0.55 \\
2.09\end{array}$ & $\begin{array}{l}5.47 \\
0.54 \\
2.03\end{array}$ & $\begin{array}{l}0.02 \\
0.47 \\
0.16\end{array}$ & + \\
\hline $\begin{array}{l}\text { HETERÓTROFOS/Overall heterotrophs } \\
\text { Fósforo total/TP } \\
\text { Peces/Fish } \\
\text { TP * Fish }\end{array}$ & $\begin{array}{l}3.01 \\
0.59 \\
0.63\end{array}$ & $\begin{array}{r}17.36 \\
3.37 \\
3.61\end{array}$ & $\begin{array}{l}0.0001 \\
0.07 \\
0.06\end{array}$ & + \\
\hline $\begin{array}{l}\text { PLANCTON TOTAL/Overall plankton } \\
\text { Fósforo total/TP } \\
\text { Peces/Fish } \\
\text { TP * Fish }\end{array}$ & $\begin{array}{l}3.82 \\
0.83 \\
1.03\end{array}$ & $\begin{array}{r}18.49 \\
4.02 \\
4.99\end{array}$ & $\begin{array}{l}0.0001 \\
0.05 \\
0.03\end{array}$ & $\begin{array}{c}+ \\
- \\
+/=\end{array}$ \\
\hline
\end{tabular}

La variabilidad de las biomasas de bacterias y fitoplancton consumible por herbívoros disminuye con la eutrofia ( $\mathrm{p}<0.05$; Tabla 4). Los demás grupos funcionales no se ven afectados. La paradoja del enriquecimiento ( $3^{\mathrm{a}}$ hipótesis), por tanto, no se cumple y, lo que es más sorprendente, hemos observado una mayor estabilidad de las poblaciones planctónicas de menor tamaño a medida que aumenta la concentración promedio de fósforo total en los lagos estudiados.
Fitoplancton, rotíferos y copépodos dependen directamente del fósforo $(\mathrm{p}<0.02-0.003$; Tabla 5). Cladóceros y bacterias dependen directa e inversamente, respectivamente, de la presencia de peces ictiófagos $(\mathrm{p}<0.02-0.03)$. En las lagunas eutróficas y con peces ictiófagos, la cantidad de plancton total es menor $(\mathrm{p}<0.03)$. En las lagunas con menos fósforo, la presencia de peces ictiófagos no afecta al plancton $(\mathrm{p}<0.03)$. Por lo tanto, el efecto del recurso limitante afecta 
Tabla 6. ANOVA bifactorial de comprobación de los efectos del enriquecimiento en fósforo y de la presencia de peces ictiófagos sobre la estructura de tamaños de la comunidad planctónica. Puede haber dos tipos de interacción factorial y, de ahí, los dos signos en el apartado Fósforo * Peces; nc: sin cambios.

\begin{tabular}{lcccc}
\hline & MSS & F & p & $\begin{array}{l}\text { Signo/ } \\
\text { Sign }\end{array}$ \\
\hline Fósforo total/TP & 0.058 & 9.20 & 0.004 & - \\
Peces/Fish & 0.054 & 9.08 & 0.004 & - \\
TP * Fish & 0.051 & 8.60 & 0.005 & $-/ n c$ \\
\hline
\end{tabular}

a fitoplancton y rotíferos, pero no a bacterias, es decir, hay un efecto "bottom-up" que no alcanza a los cladóceros ni atañe a parte del alimento de éstos (las bacterias). Además, la presencia de peces ictiófagos incide favorablemente sobre aquéllos y perjudica a las bacterias, lo cual es lo esperable de acuerdo con la idea de la cascada trófica, pero dicha presencia carece de efecto sobre las demás comunidades planctónicas. Dicho de otro modo, la cascada trófica resulta incompleta. Así, vemos que la $4^{\mathrm{a}}$ hipótesis se confirma si adoptamos una hipótesis de interacción de fuerzas y no una de cascada trófica.

En ausencia de peces ictiófagos, el enriquecimiento en fósforo favorece las biomasas de los tamaños menores del plancton $(\mathrm{p}<0.004$; Tabla 6). Sin embargo, en presencia de peces ictiófagos, no hay efecto del fósforo sobre los tamaños. Por tanto, los tamaños planctónicos se ven afectados de manera antagónica por estos dos factores: la presencia de peces ictiófagos impide el efecto del enriquecimiento en fósforo sobre la estructura de tamaños, efecto que sí tenía lugar cuando no hay ictiófagos. La $5^{\text {a }}$ hipótesis se complica.

\section{DISCUSIÓN}

Este trabajo ha intentado comprobar o refutar-de manera sencilla- una serie de hipótesis, generadas en las últimas décadas, sobre las redes tróficas pelágicas en relación con el enriquecimiento en el nutriente limitante. El resultado ha sido ambivalente: no todas las hipótesis se han comprobado, pero las respuestas de la comunidad planctónica al enriquecimiento resultan más complejas e interesantes que las corrientemente aceptadas. Por ello, nos ha parecido interesante pasar de estudios meramente descriptivos a estudios de refutación de hipótesis, aún comparativamente escasos en ecología (Peters, 1991). Este ejercicio es económico y animamos a otros limnólogos con escasos recursos a practicarlo.

Una crítica que se podría hacer a nuestros resultados apuntaría al pequeño número de lagos con el que hemos trabajado, aunque ello se tenga en cuenta en la significación estadística de las pruebas realizadas. Sin embargo, en el sentido popperiano clásico del que somos deudores aquí, la refutación es válida en tanto haya datos que la apoyen (Popper, 1980). Los resultados obtenidos por nosotros son, por lo tanto, más ricos que los inicialmente previstos si hubiésemos conseguido comprobar las cinco hipótesis. Dado que éstas ya presuponían algunas ideas contra el sentido común ("paradoja" en una de las acepciones del Diccionario de la Lengua es "especie extraña y opuesta al común sentir de los hombres"; RAE, 1970), nos atrevemos a hablar de nuestros resultados como de un enriquecimiento de las paradojas.

Para empezar, no hemos comprobado totalmente la relación entre enriquecimiento y biomasa promedio (Fig. 2), pese a haber sido postulado explícita e implícitamente por numerosos autores (Hanson \& Peters, 1984; Smith, 1991; Del Giorgio \& Gasol, 1995; Jeppesen et al., 2000). Una explicación para nuestro resultado es que los crustáceos se vieran muy perjudicados por el desarrollo de las cianofíceas coloniales y filamentosas, propio de ambientes hipertróficos (Elser \& Goldman, 1990; Gliwicz, 1990). Sin embargo, esto no ha sido observado en los lagos daneses de mayor grado trófico, donde sí se presentan grandes biomasas de crustáceos planctónicos (Jeppesen et al., 2000). Por lo tanto, nuestro resultado representa una refutación de la hipótesis corrientemente aceptada, lo cual exigiría la propuesta de otra más global.

La segunda hipótesis que intentamos comprobar era la de la respuesta unimodal de la riqueza específica de las distintas comunidades pelági- 
cas el enriquecimiento en el nutriente limitante. Carecemos de datos sobre la riqueza específica de crustáceos, pero los de fitoplancton y rotíferos no abonaron la hipótesis (Fig. 3), en contra de lo sugerido por Dodson et al. (2000) y Jeppesen et al. (2000). En realidad, algunos de los mecanismos que Dodson et al. (2000) proponen para explicar las pautas observadas por ellos -y cuya varianza explicada sólo asciende al $50 \%$ en el mejor de los casos (Figura 3 de su artículo)- también darían cuenta de la hipótesis alternativa más ajustada a nuestros resultados: la de que la riqueza específica aumenta con la productividad o con su correlato, el enriquecimiento en el nutriente limitante. Además, una revisión anterior sobre los estudios efectuados sobre la relación riqueza-productividad (Waide et al., 1999) dio como resultado que sólo en un $40 \%$ de los mismos se presentaban pautas unimodales. De todos modos, quizá fuera más conveniente abandonar esa hipótesis de unimodalidad a la hora de explicar la variabilidad de las pautas observadas en el tema de la riqueza específica frente el enriquecimiento en el nutriente limitante y considerar otras, tales como la de la perturbación intermedia (Connell, 1978), la del impacto del consumo por herbívoros (Proulx \& Mazumder, 1998) o la de la riqueza específica como variable explicativa de la productividad global (Lehman \& Tilman, 2000) y no al revés que es lo que se supone en la hipótesis de Dodson et al. (2000).

Tampoco hemos podido comprobar uno de los aspectos de la paradoja del enriquecimiento: el de que éste desestabiliza a los grupos funcionales (Tabla 4). Sin embargo, esta idea ya ha sufrido varias refutaciones en estudios de campo (McCauley \& Murdoch, 1990; McCauley et al.., 1988). Con objeto de respetar una hipótesis aparentemente atractiva, se han propuesto numerosas modificaciones teóricas de la misma que incluyen aspectos de omnivoría (McCann \& Hastings, 1997), heterogeneidad espacial (Jansen, 1995) y heterogeneidad dentro de los niveles tróficos (Abrams, 1993). En el caso del Parque del Sureste, la abundancia de copépodos, cuya biomasa a menudo sobrepasa a la de cladó- ceros (Fig. 2) y su reconocido carácter más omnívoro que el de éstos últimos (Sprules \& Bowerman, 1988), apoyaría el efecto modificador de la omnivoría sobre la paradoja del enriquecimiento. Por otro lado, los lagos estudiados son ricos en ciprínidos (Barbus spp., Cyprinus carpio, Lepomis gibbosus, Rutilus spp., Tinca tinca, etc.: García-Avilés et al., 1999), los cuales suelen tener una alimentación omnívora, si bien preponderantemente bentónica (Doadrio, 2001); además, poco a poco ya se va abriendo paso la idea de que los peces lacustres se alimentan en todos los hábitats (Van der Zanden \& Vadeboncoeur, 2002). Así, y de acuerdo con los resultados teóricos de McCann \& Hastings (1997) para situaciones de no-equilibrio, que son las propias de la mayoría de los ecosistemas reales (De Angelis \& Waterhouse, 1987), la gran abundancia de elementos omnívoros en estos lagos contribuiría a estabilizar los grupos funcionales de la red pelágica. Tampoco debemos descartar el efecto estocástico atribuible al escaso número de muestras, pero ello no nos impide la comparación entre lagos, pues los muestreos se realizaron en campañas muy rápidas, dentro de un territorio que comparte un clima y unas características conservativas del agua comunes. En realidad, en este tema resulta imposible comprobar los mecanismos responsables de los procesos observados porque la complejidad del medio natural determina la aparición de numerosos efectos indirectos, producto de interacciones secundarias entre factores (Polis \& Strong, 1996).

Por otro lado, nuestros datos muestran que el efecto de la red trófica se interrumpe en los cladóceros, mientras que el del recurso limitante lo hace en los copépodos (Tabla 5). Esta desconexión parcial -que los autores sajones denominan "moderate strength"- se ha observado en estudios experimentales con microcosmos (Ortega Mayagoitia, 2001), mesocosmos (Brett \& Goldman, 1997) y en lagos (Carpenter \& Kitchell, 1993b) y determina que resulte más adecuado a la realidad el hablar de "goteo/chorrito trófico" (McCann et al., 1998) y no de "cascada trófica". Dicho goteo vendría impues- 
to por la complejidad de la red trófica, particularmente en los niveles intermedios, es decir, la heterogeneidad de los hábitos alimenticios del zooplancton, que consume recursos en varios niveles (Adrian \& Frost, 1993; Jack \& Gilbert, 1993), y la presencia de peces bentófagos en nuestros lagos serían los motivos principales responsables de las pautas observadas en este estudio. En realidad, nuestros resultados se ven mejor explicados por la hipótesis de la interacción entre fuerzas ascendentes y descendentes de la red trófica, que puede generar desconexiones entre los eslabones (McQueen et al., 1989).

Finalmente, el efecto combinado de predadores en la cúspide de la red trófica y de nutrientes sobre el espectro de tamaños planctónicos se ha comprobado (Tabla 6), al igual que en otros estudios (Cottingham, 1999; Mazumder et al., 1988). Sin embargo, la presencia de peces ictiófagos y el enriquecimiento en fósforo afectan antagónicamente a los espectros. Y por si esto fuera poco, existen también estudios en los que no se aprecian efectos de los peces sobre los tamaños del plancton (Baca \& Threlkeld, 2000). Así que este resultado final recalca una vez más la necesidad de otras hipótesis más globales para explicar los efectos del enriquecimiento en el nutriente limitante sobre las redes tróficas pelágicas de los lagos. Por ahora, no nos resulta claro cuáles deberían ser esas hipótesis. La exploración de la sugerencia de la especificidad de los ecosistemas mediterráneos, con mayores duraciones de las fases de crecimiento en el año, resultado de las mayores dosis de radiación a lo largo del año, podría merecer la pena en relación con la hipótesis de regulación de la estequiometría de las redes tróficas por el cociente luz:nutriente limitante (Sterner et al., 1997), pero ésta habría que modificarla, pues es una hipótesis que considera valores promediados de luz en la columna de agua y no dosis de luz a lo largo del año.

\section{AGRADECIMIENTOS}

Este trabajo se realizó con una ayuda para el estudio físico-químico de los lagos del Parque
Regional del Sureste, pagado por la Consejería de Medio Ambiente y Desarrollo Regional de la Comunidad Autónoma de Madrid. La ayuda del Director del Parque, Adolfo Bello, y de los agentes forestales del mismo nos resultó muy de agradecer. En los muestreos y análisis químicos participaron Palmira Riolobos, Neftalí Roblas, Juana Hidalgo, Youssef Himi y Salvador Sánchez Carrillo; el estudio no hubiera podido realizarse sin ellos. Carmen Rojo leyó atentamente el manuscrito y sugirió importantes mejoras. Durante la presentación pública del trabajo en el XI Congreso Español de Limnología, varios asistentes realizaron interesantes críticas y sugerencias que hemos incorporado al texto. Finalmente, la atenta lectura y las sugerencias del revisor nos ayudaron sobremanera y han mejorado claramente el producto final.

\section{BIBLIOGRAFÍA}

ABRAMS, P. A. 1993. Effects of increased productivity on the abundances of trophic levels. Am. Nat., 141: 351-371.

ADRIAN, R. \& T. M. FROST. 1993. Omnivory in cyclopoid copepods: comparison of algae and invertebrates as food for three, differently sized species. J. Plankton Res., 15: 643-658.

ÁlVAREZ COBELAS, M., P. RIOLOBOS, Y. HIMI, S. SÁNCHEZ CARRILLO, J. GARCÍA-AVILÉS \& J. HIDALGO. 2000. Estudio fisicoquímico de los ambientes estancados del Parque Regional del Sureste de la Comunidad de Madrid. Centro de Investigaciones Ambientales de la Comunidad de Madrid. Serie Documentos $n^{\circ} 29$. Consejería de Medio Ambiente y Desarrollo Regional. 67 pp.

ANDERSEN, T. 1997. Pelagic Nutrient Cycles. Springer Verlag, Berlin. 228 pp.

APHA, 1989. Standard Methods for the Examination of Water and Wastewater. $17^{\text {th }}$ edition. Washington D.C.

BACA, R. M. \& S. T. THRELKELD. 2000. Using size distributions to detect nutrient and sediment effects within and between habitats. Hydrobiologia, 435: 197-211.

BACHMAN, R. W. \& D. E. CANFIELD. 1992. Use of an alternative method for monitoring total nitrogen concentrations in Florida lakes. 
Hydrobiologia, 323: 1-8.

BRATBAK, G. 1985. Bacterial biovolume and biomass estimations. Appl. Environm. Microbiol., 49: 1488-1493.

BRETT, M. T. \& C. R. GOLDMAN. 1997. Consumers versus resource control in freshwater pelagic food webs. Science, 275: 384-386.

BROWNE, R. A. 1981. Lakes as islands: biogeographic distribution, turnover rates, and species composition in the lakes of central New York. $J$. Biogeogr., 8: 75-83.

CARPENTER, S. R. \& J. F. KITCHELL. (eds.) 1993a. The Trophic Cascade in Lakes. Cambridge University Press, Cambridge. 385 pp.

CARPENTER, S. R. \& J. F. KITCHELL. 1993b. Simulation models of the trophic cascade: predictions and evaluations. In The Trophic Cascade in Lakes. S. R. Carpenter \& J. F. Kitchell (eds): 310331. Cambridge University Press, Cambridge.

CARPENTER, S. R., J. F. KITCHELL \& J. R. HODGSON. 1985. Cascading trophic interactions and lake productivity. BioScience, 35: 634-639.

COHEN, J. E., F. BRIAND \& C. M. NEWMAN. 1990. Community Food Webs: Data and Theory. Springer Verlag, Berlin. 308 pp.

CONNELL, J. H. 1978. Diversity in tropical rain forests and coral reefs. Science, 199: 1304-1310.

COTTINGHAM, K. L. 1999. Nutrients and zooplankton as multiple stressors of phytoplankton communities: evidence from size structure. Limnol. Oceanogr., 44: 810-827.

DE ANGELIS, D. L. 1992. Dynamics of Nutrient Cycling and Food Webs. Chapman \& Hall, London. $270 \mathrm{pp}$.

DE ANGELIS, D. L. \& J. C. WATERHOUSE. 1987. Equilibrium and nonequilibrium concepts in ecological models. Ecol. Monogr., 57: 1-21.

DEL GIORGIO, P. A. \& J. M. GASOL. 1995. Biomass distribution in freshwater plankton communities. Am. Nat., 146: 135-152.

DOADRIO, I. (ed.), 2001. Atlas y Libro Rojo de los Peces Continentales de España. Dirección General de Conservación de la Naturaleza y Museo Nacional de Ciencias Naturales (CSIC), Madrid. 364 pp.

DODSON, S. I., S. E. ARNOTT \& K. L. COTTINGHAM. 2000. The relationship in lake communities between primary productivity and species richness. Ecology, 81: 2662-2679.

ELSER, J. J. \& C. R. GOLDMAN. 1990. Zooplankton effects on phytoplankton in lakes of contrasting trophic status. Limnol. Oceanogr., 36: 64-90.

FRETWELL, S. D. 1987. Food chain theory: the central theory of ecology? Oikos, 50: 291-301.

GARCÍA-AVILÉS, J., N. ROBLAS \& J. HIDALGO. 1999. Biodiversidad de los humedales del Parque Regional del Sureste. I. Vertebrados acuáticos. Centro de Investigación Ambientales de la Comunidad de Madrid. Serie Documentos n ${ }^{\circ} 28$. Consejería de Medio Ambiente y Desarrollo Regional. 65 pp.

GLIWICZ, Z. M. 1990. Why do cladocerans fail to control phytoplankton blooms?. Hydrobiologia, 200/201: 83-97.

HANSON, J. M. \& R. H. PETERS.1984. Empirical prediction of crustacean zooplankton biomass and profundal benthos biomass in lakes. Can. J. Fish. Aquat. Sci., 41: 439-445.

HECKY, R. E. \& P. KILHAM. 1988. Nutrient limitation of phytoplankton in freshwater and marine environments: a review of recent evidence on the effects of enrichment. Limnol. Oceanogr., 33: 796-822.

HILLEBRAND, H., C. D. DÜRSELEN, D. KIRSCHTEL, U. POLLINGHER \& T. ZOHARY. 1999. Biovolume calculation for pelagic and benthic microalgae. J. Phycol., 35: 403-424.

HOBBIE, J. E., R. DALEY \& S. JASPER. 1977. Use of Nucleopore filters for counting bacteria by fluorescence microscopy. Appl. Environm. Microbiol., 33: 1225-1228.

JACK, J. D. \& J. J. GILBERT. 1993. Susceptibilities of different-sized ciliates to direct suppression by small and large cladocerans. Freshwat. Biol., 29: 19-29.

JANSEN, V. A. A. 1995. Regulation of predator-prey systems through spatial interactions: a possible solution to the paradox of enrichment. Oikos, 74: 384-390.

JEPPESEN, E., J. P. JENSEN, M. SØNDERGAARD, T. LAURIDSEN \& F. LANDKILDHUS. 2000. Trophic structure, species richness and biodiversity in Danish lakes: changes along a phosphorus gradient. Freshwat. Biol., 45: 201-218.

LEHMAN, C. L. \& D. TILMAN. 2000. Biodiversity, stability, and productivity in competitive communities. Am. Nat., 156: 534-552.

LINDEMAN, R. L. 1942. The trophic-dynamic aspect of ecology. Ecology, 23: 399-418.

LUND, J. W. G., C. KIPLING \& E. D. LE CREN. 1958. The inverted microscope method of estima- 
ting algal numbers, and the statistical basis of estimations by counting. Hydrobiologia, 10: 143-170.

MARKER, A. F. H., E. A. NUSCH, H. RAI \& B. RIEMANN. 1980. The measurement of photosynthetic pigments in freshwater and standardization of methods: conclusions and recommendations. Arch. Hydrobiol., Ergebn. Limnol., 14: 91-106.

MAZUMDER, A., D. J. McQUEEN, W. D. TAYLOR, D. R. S. LEAN. 1988. Effects of fertilization and planktivorous fish (yellow perch) predation on size distribution of particulate phosphorus and assimilated phosphate: large enclosures experiments. Limnol. Oceanogr., 33: 421-430.

McCANN, K. S. \& A. HASTINGS. 1997. Re-evaluating the omnivory-stability relationships in food webs. Proc. R. Soc. London B, Biol. Sci., 264: 1249-1254.

McCANN, K. S., A. HASTINGS \& D. R. STRONG. 1998. Trophic cascades and trophic trickles in pelagic food webs. Proc. R. Soc. London B, Biol. Sci., 265: 205-209.

McCAULEY, E. 1984. The estimation of the abundance and biomass of zooplankton in samples. In: A Manual on the Assessment of Secondary Production in Freshwaters. J.A. Downing \& F.H. Rigler (eds): 228-265. Blackwell, Oxford.

McCAULEY, E. \& W. W. MURDOCH. 1990. Predator-prey dynamics in environments rich and poor in nutrients. Nature, 343: 455-457.

McCAULEY, E., W. W. MURDOCH \& S. WATSON. 1988. Simple models and the variation in plankton densities among lakes. Am. Nat., 132: 383-403.

McQUEEN, D. J., J. R. POST \& E. L. MILLS. 1986. Trophic relationships in freshwater pelagic ecosystems. Can. J. Fish. Aquat. Sci., 43: 1571-1581.

McQUEEN, D. J., M. R. S. JOHANNES, J. R. POST, T. J. STEWART \& D. R. S. LEAN. 1989. Bottomup and top-down impacts on freshwater pelagic community structure. Ecol. Monogr., 59: 289-309.

OKSANEN, L., S. D. FRETWELL, J. ARRUDA \& P. NIEMELA. 1981. Exploitation ecosystems in gradients of primary production. Am. Nat., 118: 240261.

ORTEGA MAYAGOITIA, E. 2001. El plancton de Las Tablas de Daimiel: factores que controlan su dinámica. Tesis Doctoral. Univ. Valencia. 197 pp.

PERSSON, A., L. A. HANSSON, C. BRÖNMARK, P. LUNDBERG, L. B. PETTERSON, L. GREENBERG, P. A. NILSSON, P. NYSTRÖM, P. ROMARE \& L. TRANVIK. 2001. Effects of enrichment on simple aquatic food webs. Am. Nat., 157: 654-669.

PETERS, R. H. 1991. A Critique for Ecology. Cambridge University Press, Cambridge. 384 pp.

POLIS, G. A. \& D. R. STRONG. 1996. Food web complexity and community dynamics. Am. Nat., 147: 813-846.

POPPER, K. R. 1980. The Logic of Scientific Discovery. $10^{\text {th }}$ impression. Hutchinson, London. $556 \mathrm{pp}$.

POURRIOT, R. 1977. Food and feeding habits of Rotifera. Arch. Hydrobiol. Ergebn. Limnol., 8: 243-260.

PRAIRIE, Y. T. \& D. F. BIRD. 1989. Some misconceptions about the spurious correlation problem in the ecological literature. Oecologia, 81: 285-288.

PROULX, M. \& A. MAZUMDER. 1998. Reversal of grazing impact on plant species richness in nutrient-poor vs. nutrient-rich ecosystems. Ecology, 79: 2581-2592.

REAL ACADEMIA ESPAÑOLA, 1970. Diccionario de la Lengua Española. 19a edición. Madrid. 1424 pp

ROBLAS, N. \& J. GARCÍA-AVILÉS. 1997. Valoración ambiental y caracterización de los sistemas acuáticos leníticos del Parque Regional en torno a los ejes de los cursos bajos de los ríos Manzanares y Jarama. Centro de Investigación Ambientales de la Comunidad de Madrid. Serie Documentos $\mathrm{n}^{\circ}$ 24. Consejería de Medio Ambiente y Desarrollo Regional. 128 pp.

ROSENZWEIG, M. L. 1971. Paradox of enrichment: destabilization of exploitation ecoystems in ecological time. Science, 171: 385-387.

ROTT, E. 1981. Some results from phytoplankton counting intercalibrations. Schweiz. Z. Hydrol., 43: 34-62.

SMITH, V. H. 1991. Phytoplankton responses to eutrophication in inland waters. In: Introduction to Applied Phycology. I. Akatsuka (ed): 231-249. SPB Academic Publishers, The Hague.

SPRULES, W. G. \& J. E. BOWERMAN. 1988. Omnivory and food chain length in zooplankton food webs. Ecology, 69: 418-426.

STERNER, R. W., J. J. ELSER, E. J. FEE, S. J. GUILFORD \& T. H. CHRZANOWSKI. 1997. The light:nutrient ratio in lakes: the balance of energy and materials affects ecosystem structure and process. Am. Nat., 150: 663-684.

VAN DER ZANDEN, M. J. \& Y. VADEBONCOEUR. 2002. Fishes as integrators of benthic and pelagic food webs in lakes. Ecology, 83: 21522161. 
VIDONDO, B., Y. T. PRAIRIE, J. M. BLANCO \& C. M. DUARTE. 1997. Some aspects of the analysis of size spectra in aquatic ecology. Limnol. Oceanogr., 42: 184-192.

VOLLENWEIDER, R. A. 1968. Scientific Fundamentals of the Eutrophication of Lakes and Flowing Waters, with special reference to Nitrogen and Phosphorus. OECD Report, Paris. 159 pp.
WAIDE, R. B., M. R. WILLIG, C. F. STEINER, G. MITTELBACH, L. GOUGH, S. I. DODSON, G. P. JUDAY \& R. PARMENTER. 1999. The relationship between productivity and species richness. Ann. Rev. Ecol. Syst., 30: 257-300.

WILLIAMS, C. B. 1964. Patterns in the Balance of Nature and related Problems in quantitative Ecology. Academic Press, London. 324 pp. 
